\title{
Informática nos tribunais e a teoria do risco global ${ }^{1}$
}

\author{
Roberto Fragale Filho \\ Fernando de Castro Fontainha*
}

Resumo O trabalho visa estabelecer uma interface entre as preocupações que envolvem os perigos inerentes à aplicação da informática nos tribunais e a moderna teoria social do risco. Admitindo a informatização dos tribunais brasileiros como um fenômeno do nosso tempo, pretende-se contextualizar o risco como muito mais que uma preocupação transversal, mas como paradigma da contemporaneidade, uma vez adotado o conceito de modernidade reflexiva formulado por Ulrich Beck, onde os laços de confiança e agregação social (notadamente nos sistemas peritos de Anthony Giddens) se liquefazem. Em especial é feita a análise acerca dos riscos globais aos quais nos expomos ao dedicar parte da administração de nossas relações coletivas a recursos computacionais, virtuais (com ênfase em artigo de Josh Van Loon).

Palavras-chave ciência, técnica e modernidade, sociedade do risco global, informatização dos tribunais, Ulrich Beck, modernidade reflexiva

\begin{abstract}
This paper aims to establish an interface between the concern that involves the inherent dangers of informatics resources applied to courts and modern social risk theory. Admitting Brazilian courts informatization as a phenomenon of our time, our intent is to contextualize risk as much more than a transversal concern, but a paradigm of our days, once adopted the reflexive modernity concept as conceived by Ulrich Beck, where the trust and social aggregation bonds (specially Giddens's expert systems) melt. An analysis is specially made about the global risks to which we are exposed while dedicating part of our collective relations administration to computer resources, virtual resources (with emphasis on a paper by Josh Van Loon).
\end{abstract}

Keywords science, technique and modernity, global risk society, courts' informatization, Ulrich Beck, reflexive modernity

\section{Introdução}

\footnotetext{
${ }^{1}$ Texto apresentado no Grupo de Trabalho "Sociedade da Informação", no XII Congresso Brasileiro de Sociologia, ocorrido em Belo Horizonte entre os dias 31 de maio e 3 de junho de 2005.

* Roberto Fragale Filho é Doutor em Ciência Política, professor adjunto e líder do Grupo de Pesquisas "Direito, Tecnologia e Sociedade" da Universidade Federal Fluminense; Fernando de Castro Fontainha é mestrando em Sociologia e Direito na Universidade Federal Fluminense, membro do Grupo de Pesquisas "Direito, Tecnologia e Sociedade".
} 
O recente fenômeno da informatização dos tribunais brasileiros impõe uma série de reflexões no âmbito da sociologia jurídica.

Iniciaremos adotando a cisão da modernidade em duas fases distintas conforme proposta de Beck (BECK; ZOLO, 1999). A primeira, compreendendo o período entre o século XVIII até o fim do século XX, cujas características marcantes seriam uma sociedade estatal e nacional, estruturas coletivas, pleno emprego, rápida industrialização e exploração da natureza não visível. A segunda, contemporânea, marcada pela globalização, a individualização, o desemprego, o subemprego, a revolução dos gêneros e os riscos globais da crise ecológica e da turbulência dos mercados financeiros. Dita radical ou reflexiva.

Veremos como a modernidade foi marcada pelo abandono de laços de confiança como a família, a vizinhança, a religião, o feudo, para dar lugar a novos laços os quais possibilitaram uma sucessão de desencaixes e reencaixes no tempo e no espaço. A crença é substituída pela confiança. Confiança de que, aprioristicamente, o homem poderia, através da razão, dominar a natureza e transforma-la conforme seus desígnios.

Ou ainda, conforme diagnosticado em Baker e Simon, desde o advento da modernidade até o início dos anos oitenta, alguns visionários reivindicavam que a segurança incorporava a superioridade da ciência e tecnologia sobre a religião (BAKER; SIMON, 2002, p. 3).

Assim, resgatando uma matriz teórica Weberiana, chegaremos ao conceito de sistemas peritos, um dos mecanismos de desencaixe identificados por Anthony Giddens.

Porém, teremos também a oportunidade de constatar um fenômeno que se apresenta inicialmente como enigmática contradição. Se de um lado, a vida humana é mais segura na contemporaneidade do que era na primeira fase da modernidade, porque àquela época foi marcada pela certeza e a atual pelo risco?

É o tema lançado por Ulrich Beck, e ponto de observação privilegiado de onde podemos vislumbrar o processo de informatização do Poder Judiciário no Brasil, pois sob seu ângulo que se farão as luzes necessárias à fuga do dilema de Althusser: se eu perdi as chaves no escuro, não as encontrarei embaixo do poste, somente porque este está iluminado.

Enfim, este trabalho nada mais se pretende que um ensaio acerca da informatização do Poder Judiciário diante da teoria social do risco. Ao final, o estudo específico do fenômeno da informatização dos tribunais. É um fenômeno como muitos os quais poderíamos citar. E alguns ainda muito mais paradigmáticos. Casos como, após quase trinta anos do envio do homem para a lua, o mundo ter assistido estarrecido a explosão do Ônibus Espacial 'Challenger' em pleno vôo. Mas não o faremos.

\section{Modernidade: a construção de um castelo de certezas}

Um exercício teórico pode ser por qualquer um efetuado no sentido de desvendar o que fez o homem abandonar o feudo e lançar-se ao mundo globalizado. De fato, como se deu a epopéia cosmopolita que encontra seu corolário no mundo contemporâneo? Teria sido a racionalidade fator tão preponderante no desvio de paradigma de toda uma civilização? 
Encontramos uma importante janela para algumas respostas em conceitos desenvolvidos por Max Weber. Para Weber, a racionalidade humana se revela a partir da adequação entre meios $e$ fins no planejamento da ação. É desta forma que Weber rejeita o real concebido holisticamente por expoentes do iluminismo e vem a falar de várias realidades, criadas a partir de parâmetros que vão balizar a ação social, no sentido da elaboração do planejamento desta ação.

Se nos valesse o esforço de buscar em Weber máxima literal do que falamos, extrairíamos: Aquele, dentre nós, que entra num trem não tem noção alguma do mecanismo que permite ao veículo pôr-se em marcha Exceto se for um físico de profissão. Aliás, não temos necessidade de conhecer aquele mecanismo. Basta-nos poder 'contar' com o trem e orientar, conseqüentemente, nosso comportamento; [...] (WEBER, 2002, p. 30).

É certo que com a assertiva acima Weber expressa muito mais que uma proposta epistemológica, mas a própria essência de sua teoria das relações sociais. O exemplo do trem é apenas um exemplo isolado, assim, como, de outra oportunidade e em contexto diverso, o próprio Weber se referira à moda e à regularidade na formação de preços no mercado como tipos ideais (WEBER, 1944 , p. 23-24).

Por tipos ideais devemos compreender o previsível, o hodierno, o contínuo, ou seja, a racionalidade redefinida como a adequação entre meios e fins. Nas palavras do próprio Weber: "conceitos abstratos de relações, que concebemos como relações estáveis no fluxo do devir, como indivíduos históricos nos quais se processam desenvolvimentos" (WEBER, 1991, p. 117).

Outro aspecto importante do conceito chave tipo ideal, é justamente o fato de o mesmo limitar sua existência ao mundo das idéias. O capitalismo e o socialismo, para Weber, seriam dois tipos ideais, que somente em livros e representações da mente poderiam ganhar forma vital. Ou seja, capitalismo e socialismo são grandes categorias dentro das quais se pretende tipificar o modo de produção dominante em dada sociedade. Assim, o capitalismo na Alemanha e na Guatemala, estudados empiricamente, apresentam uma série de distinções que nos fariam duvidar se tratarem de gêneros englobados pela mesma espécie. De igual sorte ocorre com o socialismo Russo e o Cubano. Para tal existe o tipo ideal. A observação de determinados parâmetros similares os encaixa. Assim, para Weber, não existe capitalismo e socialismo, mas vários capitalismos e socialismos, muito embora este fato não esvazie a distinção de conteúdo.

Este brevíssimo ensaio apenas visa abrir caminho e revelar de que fonte bebeu aquele que veio a responder a pergunta: Quais laços substituíram aqueles tão consolidados como a família, a vizinhança e a religião, e foram capazes de erguer uma nova etapa civilizacional de contornos tão peculiares?

Anthony Giddens sistematizou teoricamente os mecanismos específicos que, na sua visão, foram as ferramentas para o desvio de paradigma de que tratamos: a substituição da crença pela confiança. O triunfo da razão e da ciência sobre a religião e a magia.

Porém, Giddens não se deixou envolver pela cilada normativista que nos faria entender a transição para a modernidade como um processo local, temporal, a-histórico e unívoco no tempo e no espaço. Ao desenvolver o conceito de desencaixe, com dimensões temporais e espaciais, Giddens parte da perspectiva construtivista de concepção da história da sociedade como um 
fluxo contínuo de feixes de relações sociais, dentro dos quais é possível captar desencaixes e reencaixes - no tempo e no espaço - os quais provocam transformações (GIDDENS, 1990, p. 29-37).

Desta sorte, não houve um enorme desencaixe que culminou na idade moderna. Não há fatos isolados dentro de um tempo e espaço passados que, se estudados, revelarão a chave para a compreensão do nosso tempo. Ao contrário, Giddens afirma ser característica nodal da modernidade justamente uma fase onde os desencaixes e reencaixes são de uma multiplicidade tão incalculável e imprevisível, que tornam impossível a ambição de dirigir o carro de Jagrená.

E é justamente deste ponto que podemos ver o trem de Weber recontextualizado... E a todo vapor! Isto porque Giddens vai identificar dentre os feixes que unem a história da sociedade e ainda estão por se construir o que chama de mecanismos de desencaixe associados à modernidade. Dente eles, dois notáveis exemplos são as fichas simbólicas e os sistemas peritos (GIDDENS, 1990, p. 30).

Como apenas o segundo interessa consideravelmente ao nosso propósito, basta, para caracterizar devidamente não apenas os dois citados, mas a essência dos mecanismos de desencaixe, que mencionemos que é da confiança que todos extraem sua força motriz, seja confiança na validade, universalidade e circularidade do dinheiro (ficha simbólica), seja na acuração e precisão dos sistemas peritos.

Por sistemas peritos devemos entender sistemas os quais incorporam valores como excelência técnica ou competência profissional, bastantes para induzir aos seus usuários a confiança que funcionem. É o que faz com que entremos em nossas casas sem duvidar de sua estrutura, confiar que há ciência e técnica no decolar de um avião ou mais que o mero ato de desenterrar e revirar cadáveres no aprendizado do médico. É o trem de Weber.

É evidente que poderíamos considerar um elemento de fé na confiança depositada nos sistemas peritos, entretanto, se fizermos uma configuração dos enormes aparatos que os circulam, como órgãos de proteção dos direitos dos consumidores dos sistemas, de fiscalização e regulação da atividade dos profissionais e de certificação de qualidade e procedência, veremos que esta confiança surge como valor social e historicamente construído.

A expansão marítima percebida a partir do século XVI é notável exemplo do funcionamento de um sistema perito específico como mecanismo de desencaixe. Sem grandes delongas, podemos afirmar que a criação da Escola de Sagres foi marco neste processo. Isto porque é mais razoável (i) embarcar para rumo incerto uma vez que o navio foi construído por especialistas e será operado por técnicos com auxílio de instrumentos de navegação do que (ii) embarcar para rumo incerto tendo o navio sido palco do sacrifício de um animal, o que agradaria a uma entidade mágica ou sagrada.

Poderíamos escrever um tomo apenas nos debulhando em exemplos, mas em verdade o conceito de sistemas peritos não é empregado aqui retoricamente, mas como um ponto de apoio para a compreensão da informática aplicada à vida e aos tribunais.

Desta forma, para efeitos deste trabalho, consideraremos a informática dentro da ótica dos sistemas peritos, com ênfase na confiança que os usuários nela depositam para planejar sua ação. A certeza no trem de Weber é a certeza que temos ao efetuar compras pela 'internet', ao consultar saldos bancários e veicular informações pessoais e profissionais por 'e-mail'. É a confiança do advogado ao consultar informações de processos na página do tribunal, do juiz ao firmar assinatura eletrônica em uma sentença. 
É o trem de Weber avançando sobre a modernidade à velocidade do sinal eletrônico. É o erguimento de um novo estágio civilizatório calcado na confiança, em princípio na confiança de que o homem tem obtido sucessos no desiderato de colonizar plenamente a natureza deste mundo, e quiçá de outros.

\section{Modernidade reflexiva: sobre um castelo de cartas}

Uma situação que pode metaforizar a perplexidade, o desencantamento e o mal-estar com que ultrapassamos os anos oitenta é a já citada explosão da 'Challenger' em pleno vôo. Seria o castelo de certezas da modernidade em verdade um castelo de cartas? Um sopro poderia lhe ser fatal?

Ainda Giddens afirma que em termos de perigos que circundam a vida humana estamos hoje muito melhor do que os habitantes do castelo de certezas. Na Inglaterra de 1907, estudos demonstram que aqueles que nasciam passavam a viver em um 'campo minado'. Uma entre sete crianças morria antes do primeiro ano de vida. Dentre os muitos fatores os quais garantiram uma segurança pessoal à humanidade até os anos setenta, podemos ressaltar os seguintes: água tratada, esgoto sanitário, preparo higiênico da comida, leite pasteurizado, refrigeração, aquecimento central e controle de insetos e roedores (GIDDENS, 2002, p. 109-110).

Poderíamos concluir que fazia parte dos planos de colonizar o futuro a diminuição dos riscos que circundavam a vida dos indivíduos. Poderíamos, ainda, concluir que a segunda fase da modernidade é marcada pela erradicação ou redução do elemento 'risco' a um grau insignificante no cálculo da ação social. No entanto, como veremos, a partir dos anos oitenta o risco passou a ocupar lugar de destaque, a ponto de ao nosso tempo ser alcunhada a pecha de "sociedade de risco".

Ignorado inicialmente pelas ciências humanas e sociais, o risco constou primeiramente da agenda de pesquisas dos economistas. Como conseqüência, temos como paradigma dominante para a análise de segurança e risco a teoria econômica neoclássica, os departamentos que se dedicam a este tema são repletos de economistas (ao menos nos EUA) e os termos da economia são os que adornam as discussões sobre segurança pública e regulação da segurança privada (BAKER; SIMON, 2002, p. 13).

O marco do avanço das ciências sociais sobre o tema do risco é a publicação, em 1992, da brochura "Risikogesellschaft", de Ulrich Beck, autor de tradição pós-marxista. Neste trabalho, Beck interpreta a contemporaneidade como uma segunda fase da modernidade, rejeitando tanto as teses da pós-modernidade e da simples continuidade da modernidade. Esta segunda fase é marcada pela reflexividade, ou seja, o momento em que a modernidade é forçada a olhar para traz e reconstruir ou reforçar as bases daquele castelo que parecia tão firme até os anos oitenta. Um tempo onde colonizar o futuro significa também recolonizar o passado e reconhecer a fragilidade das bases onde a pretensa era das certezas foi erguida. Se de um lado, riscos outrora considerados capitais foram minimizados a pontos notáveis, um novo rol de riscos se levanta juntamente com o fenômeno da globalização, o ímpeto de colonização e cosmopolitização de cada metro quadrado do planeta. Desta forma, laços tradicionais da primeira fase da modernidade como nação e classe vêem-se rompidos diante da natureza globalizante destes novos riscos de que fala Beck. Riscos não mais localizáveis e causadores de efeitos limitados no tempo e no espaço. Um tempo onde qualquer coisa pode representar um perigo em potencial, 
surge a responsabilidade de todos e de ninguém, a histeria convivendo com a apatia, numa escatológica perspectiva eco-fatalista onde a balança dos humores das decisões públicas e privadas pode pender para qualquer lado, globalizando os riscos da civilização (BECK, 1992, p. 36-37).

Bons exemplos podem fazer entender que não falamos de nada parecido com o juízo final, mas de perigos reais com os quais nos deparamos cotidianamente. $\mathrm{E}$, independentemente de exemplos, os riscos que caracterizam a contemporaneidade têm no seu aspecto global a suma caracterização de sua essência. Diferem-se dos demais por ter todo o espaço e tempo social como palco, fazendo romper laços originários, nunca é demais repetir, como classe e nação, os quais substituíram outrora a família, a vizinhança e a religião. Estamos falando de ameaças como doença da vaca-louca, chuva ácida, desastres nucleares e os potenciais riscos que envolvem a manipulação genética de organismos (BAKER; SIMON, p. 20-21).

É bastante, portanto, para a caracterização dos riscos que falamos, a expressão sociedade do risco global. Nela, a desvalorização cambial de títulos alemães pode provocar demissão em massa em Cingapura. Um desavisado guatemalteca pode ingerir comida contaminada por uma praga do Canadá. E sabe-se lá a que riscos está exposto o gado europeu que come soja transgênica brasileira. É a perspectiva de um relativo descontrole diante da capacidade de identificar e isolar os riscos no tempo e espaço que gera esta relação interpenetrante entre histeria e apatia.

Doravante, devemos considerar em que termos teóricos e práticos operou-se este verdadeiro desvio de paradigma capaz de dividir a modernidade em duas. A fina-flor do senso comum, alimentada por uma tradição normativista principalmente de juristas e filósofos, alardeia por todo o canto que existe uma radical separação entre teoria e prática, dois mundos absolutamente separados. Um deles, o dos práticos, que seriam os heróis e mártires da transformação social. Outro, o dos cientistas e pensadores, figuras descoladas e alienadas do mundo à sua volta.

Ensaiando um início de desconstrução desta concepção e avanço da discussão que até agora vínhamos travando, trazemos à baila a Teoria da Utilidade formulada por Jeremy Bentham (1979). Segundo sua teoria, a natureza teria posto o gênero humano sob o domínio de dois senhores: a dor e o prazer. A base de sua filosofia moral - o Princípio da Utilidade - era calcada no planejamento da ação humana de forma a proporcionar o máximo de prazer com o mínimo possível de dor. Numa situação ideal, a ação humana a qual incorporaria toda a excelência moral seria aquela que proporcionasse o prazer absoluto e nenhuma dor. Portanto, a conformidade com o princípio da utilidade está condicionada a tendência que a ação tem de aumentar a felicidade mais que diminuí-la.

É a expressão do utilitarismo, que além de Bentham teve em Thomas Hobbes e John Stuart Mill seus principais formuladores. O utilitarismo, muito mais que uma teoria abstrata, foi a expressão de um modo de pensar e agir dominante. Da orientação da vontade do monarca, passando pelos parâmetros de atribuição de políticas públicas até chegar aos mais singelos atos do cotidiano, como criar um filho ou dirigir um carro, o princípio da utilidade foi o paradigma que orientou a ação na modernidade. Dor e prazer.

Decerto alguns autores ainda vêem no utilitarismo o paradigma do nosso tempo. Peter Singer encontra nesta teoria o fundamento de validade para a causa da libertação dos animais. Crê que os animais, por possuírem sistema nervoso, portanto capacidade de identificar e quantificar intimamente sentimentos como dor e prazer, possuem o pré-requisito necessário para ter interesses de uma forma geral, arrematando que os mesmos devem ser satisfeitos (SINGER, 2002, p. 7). 
Sem assumir uma posição de radical ruptura, cremos que encontraremos em algo semelhante a um neo-utilitarismo o novo paradigma. Porque não um risco-utilitarismo, ou, em outras e mais populares palavras, a teoria do custo-benefício? Uma ação é aprovada na medida em que proporciona mais benefícios que custos. Assim, se ações forem hierarquizadas, o método é o da efetividade do custo. Baseados em critérios morais, políticos e pessoais, os argumentos intelectuais apenas embasam o que já foi decidido. Primeiro a boa sociedade, a boa vida e um lugar para si... Explicações depois (DOUGLAS; WILDAVSKY, 1982, p. 69-82). ${ }^{2}$

Esta reflexão, que reside na fronteira que o senso-comum estabeleceu entre teoria e prática, a partir de uma sensata leitura de seus reflexos teóricos e cotidianos veremos como permeia e é a nova orientação, a orientação da 'modernidade reflexiva', a ciência e arte de evitar riscos ao menor custo. Talvez por isto não se libertem os animais. A concepção de que não tinham alma deu vez à de que faziam parte da irracionalidade, ou seja, parte da natureza que se visava colonizar. Hoje não se pode liberta-los pois sua natureza é completamente avessa aos benefícios, ou, ainda, aos lucros.

Este novo paradigma, somado ao desencantamento da racionalidade como mestra da natureza, tem posto a ciência sob constante desafio, o qual reencaixa o conhecimento além da verdade e do iluminismo. Para Beck, chama-se 'cientifização reflexiva' a nova tendência de não mais considerar o mundo como um universo dado de coisas, mas como uma dinamicidade de fatores onde a tarefa primordial é estabelecer os parâmetros de segurança. A transformação de erros e riscos em oportunidades para expansão e perspectivas para o desenvolvimento da ciência e tecnologia geralmente tendem em primeiro lugar imunizar o desenvolvimento científico contra a crítica da modernidade e da civilização, tornando-o ultra-estável para se pronunciar (BECK, 1992, p. 155-163).

No ritmo do 'adeus verdade, olá confiança', podemos afirmar que ativou-se o que alguns autores chamam de modo dois da ciência. Um modo onde o cientista se transforma em perito e a ciência em técnica (arte e graça de evitar riscos). A ciência se cerca de um ceticismo e vai perdendo sua função primordial de falar a verdade (ROSE, H., 2002, p. 74-75).

No caminho da lógica de custo-benefício, à ciência fica relegada a tarefa de patrulhamento epistemológico da modernidade reflexiva. Esgotada sua incursão de conteúdo sobre o real, cabe à ciência revelar e desvelar os riscos reais. Não poderíamos chegar a esta constatação sem mencionar René Descartes, filósofo para o qual um homem precavido valia por um cientista. Sem querer menosprezar sua notória contribuição ao pensamento universal, não se pode negar que se tratou de um pensador que representava os mais mirabolantes estratagemas para escapar das ciladas do não-conhecimento. Evidentemente que não tratamos de obras como Dióptrica, Meteoros ou mesmo do Tratado da luz ou da vida, dedicadas ao estudo dos fenômenos físicos. Mas no Discurso sobre o método e nas Meditações podemos perceber de quantas precauções se cercava, sob pena de, não o fazendo, estar incorrendo em um desvio da ciência. Dois exemplos são o bastante para ilustrarmos o que afirmamos.

Ao expor sua segunda máxima da lógica, Descartes decide por ser firme e inarredável em suas ações, e em seguir com retidão suas opiniões mais duvidosas como se indubitáveis fossem. Justifica esta postura metodológica com a alegoria do viajante perdido na floresta, como se ele mesmo estivesse na floresta do não-conhecimento e precisasse sair para a verdade. Se o viajante ficar volteando, revendo suas posições quanto ao caminho mais acertado, mais demorará para

\footnotetext{
${ }^{2}$ Ver também Douglas (2002).
} 
sair da floresta que se tivesse escolhido uma direção e sentido constantes, mantendo-a mesmo quando esta parecesse a pior opção (DESCARTES, 1996, p. 48-85).

Porém a alegoria que mais ilustra o rigor metodológico que aqui visamos ilustrar encontra-se nas Meditações. Após reafirmar sua credulidade em um Deus verdadeiro que é a soberana fonte da verdade, realça a importância de criar para si a representação psicológica de, no lugar de um Deus, um gênio maligno que, não menos ardiloso e enganador que poderoso, emprega todos seus artifícios em engana-lo. Um gênio maligno que não teria, como Deus, criado o céu, a terra, os corpos e almas - enfim, um mundo real de coisas dadas - mas os teria feito representar nas mentes como ilusões, como um mundo falso, tendente a nos fazer ter um juízo equivocado sobre a realidade (DESCARTES, 1996, p. 262-263).

A segunda alegoria é tão importante para a presente reflexão que alguns autores chegam a identificar a volta deste gênio maligno cartesiano na chamada ciência no modo dois. É o caso de François Ewald, que caracteriza o princípio da precaução como ponto central da agenda da modernidade reflexiva, descolando-a do mundo real e fazendo-a olhar com desconfiança para o mundo até então construído sob a égide da ciência e tecnologia (EWALD, 2002, p. 294-297). É o gênio maligno puxando os freios do trem de Weber. É o momento em que a modernidade pára e olha para traz... E leva um grande susto.

Porém todo este prognostico não pretende de forma alguma induzir uma teoria do caos social, da hecatombe do universo. Apenas esperamos compreender o nosso tempo. Não estamos falando, por outro lado, de uma teoria insossa e normativa, mas de uma tendência que predomina nos dias de hoje e afeta de forma nodal nosso cotidiano. Ao contrário do que o cinema previa para uma sociedade pós-moderna, os profissionais do risco são pessoas comuns com vidas 'ordinárias', que apenas trocaram de eixo em sua atividade técnico-profissional. Os profissionais do risco não são operadores de grandes sistemas de monitoramento do mundo da vida, operadores de um gigante "Big Brother Mundo". Nem mesmo soldados altamente armados na luta contra as máquinas que querem nos substituir na escala evolutiva. São profissionais que sempre existiram na modernidade.

O exemplo de Nikolas Rose nos é bastante para ilustrar o quanto a modernidade reflexiva vem alterando a subjetividade dos profissionais pela necessidade de preocupação primordial em evitar e gerenciar riscos. No caso de Rose, é escolhido como objeto o universo dos psiquiatras. Para os psiquiatras do nosso tempo, não é mais balizar do diagnóstico do paciente valores como reabilitação, cura e re-socialização. Deram lugar a estes valores o controle e prevenção sobre os riscos que determinado paciente acometido de dada patologia pode proporcionar (ROSE, N., 2002, p. 219-228).

Não poderíamos concluir o capítulo sem esposar as duas considerações do próprio Beck acerca do futuro das ciências sociais. A primeira é fundada na sua discordância com a tese de Bruno Latour, segundo a qual nunca vivemos uma modernidade. Muito embora o sol nasça e morra da mesma forma, os riscos com os quais nos deparamos hoje não podem ser tomados sob o mesmo olhar que tomamos aqueles perigos e ameaças contra os quais se insurgiam os magos, sacerdotes e xamãs da antiguidade (DOUGLAS, 2002). Muito embora ainda tenham os políticos e peritos de hoje muito que aprender na erradicação e controle dos riscos com aqueles que, em seu tempo, esconjuravam os demônios e males de sua sociedade. A segunda consiste em rejeitar a interpretação fatalista que uma leitura radical da teoria do risco global poderia levar. Afirma que vem trabalhando em um modelo novo e otimista para a compreensão de nosso tempo. Uma modernidade reflexiva não necessita ser a expressão da insanidade de viver sobre a corda-bamba, sobre um castelo de cartas, onde um passo em falso pode ser fatal. Por outro lado, o elemento de reflexividade em nosso tempo consiste na revisão e reconstrução das bases da modernidade, 
processo onde a crítica, a auto-crítica, a ironia e a humanidade desempenhariam papel fundamental (BECK, 2000, p. 226-227).

\section{Informatização e risco}

Já que chegamos a este ponto não tendo partido do zero, não poderíamos deixar de enfocar o fenômeno da informatização da vida sob três eixos contextuais: (a) A informática é um sistema perito?; (b) o que é a informatização na sociedade de risco? e (c) como evitar/amenizar riscos e/ou suas conseqüências?

\section{A informática é um sistema perito?}

É evidente que a transição do segundo para o terceiro capítulo deste trabalho poderia levar a uma interpretação segundo a qual a modernidade reflexiva fez queimar na sua 'fogueira santa' toda a obra de Weber e Giddens. Porém, esta leitura seria demasiado enviesada. Se pensarmos nos sistemas peritos, como definidos por Giddens, chegaremos à conclusão de que não somente existem como ainda são laços fundamentais de desencaixe e reencaixe nas relações entre os homens dadas no espaço e tempo sociais. Ou deixaram de existir "conjunto de atividades e ditames de circunscrições técnico-profissionais que inspiram confiança cotidiana em seus usuários mais leigos'? Evidente que não. Apenas, como já tivemos a oportunidade de observar no caso dos psiquiatras, a subjetividade destas atividades técnico-profissionais foi alterada com o advento da modernidade reflexiva, ou sociedade global do risco.

Portanto, é necessário que compreendamos a informática, no contexto em que a tratamos, como um sistema perito - cuja função veremos adiante - ao qual foi incorporado o elemento segurança. Portanto, e diferentemente de outrora, a informática apenas encontra razão de ser se as relações intermediadas por recursos computacionais proporcionarem aos usuários mais segurança do que as convencionais, realizadas face-a-face.

\section{O que é a informatização na sociedade de risco?}

Antes de mais nada, a invasão de novas formas de mídia proporcionaram ao homem uma superação de limites espaço-temporais que lhe impunha a realidade física. É o trem de Weber à velocidade do sinal eletrônico criando uma sociedade global da informação. E mais que isto, globalizam o fluxo de relações humanas criando novas formas de relações de poder, de relações sociais, onde o homem se identifica como marginal diante das tecnologias de informação. Afeta crucialmente nosso dia a dia principalmente $(i)$ pela eliminação da maioria de relações que desenvolvíamos face-a-face e (ii) pela redução das distâncias espaço-temporais da circulação de documentos e informação em geral. 
São gerados novos fluxos de relações sociais, que não podem ser entendidos pelo simples estudo de sistemas de informática, pois guardam em si elementos fundamentais e ao mesmo tempo revelam uma nova política, economia, sociedade e cultura; todos de caráter global. E nesta nova socialização os usuários de alguma forma conectados por vezes encontram dificuldade para localizar a si mesmos no tempo e no espaço. Sofrem constantes desorientações, desconexões e dessincronizações.

Desta forma, quanto mais usuários se conectam e vêm participando desta nova forma de socialização, mais aumentam os riscos nos sistemas, assim como ocorre na medida da urbanização. Um vírus de computador é, portanto, tão ameaçador para esta socialização quanto a doença da 'vaca-louca' o é para a socialização face-a-face (LOON, 2000, p. 168-169).

\section{Como evitar/amenizar riscos e/ou suas conseqüências?}

Um fator de segurança nos dias de hoje está associado à noção de distribuição de responsabilidades (BAKER, 2002, p. 38-40). Uma infantaria de órgãos reguladores, instituições certificadoras, entidades de defesa do consumidor e seguradoras que garantem a restituição material de eventual perda pecuniária têm encontrado campo fértil na modernidade reflexiva para desenvolver suas atividades.

Erige-se um novo ethos, onde também faz parte do cálculo do custo-benefício a certeza da restituição/reparação derivada dos eventuais riscos da ação, calcada na múltipla responsabilização. Essa prática impede que os usuários de qualquer sistema construam sua expectativa de uso do mesmo na certeza de assumir os riscos sozinhos.

Portanto, informatizar de forma sensata na sociedade global do risco é também oferecer um sem número de aparatos que, em último grau, se responsabilizem pelas consequiências de eventuais produtos de riscos e ameaças.

\section{Informatização do judiciário hoje no Brasil}

No mundo do direito como em qualquer mundo ou sub-cultura que imaginemos, não se contém a tendência da informatização. A simples perspectiva de acompanhar um processo tramitando em juízo localizado em Passo Fundo - RS, quando de férias em Nova Dheli, bem como de transformar os maçantes autos em uma simples mídia de disco compacto não contribuem para perspectiva diversa.

Há uma propensão irresistível à informatização e isto inclui todos os tribunais brasileiros. Para melhor caracterizar este processo, é necessário estar sensível para dois recortes de seu caminho, os quais deverão ser analisados separadamente, a saber: $(a)$ a criação de instrumentos periféricos ao processo visando o maior deslocamento de seu conteúdo no tempo e no espaço; e $(b)$ a transformação dos autos escriturais em autos virtuais a partir da certificação digital dos atos processuais. 


\section{Dos sistemas periféricos}

Por sistemas periféricos devemos entender iniciativas locais e instanciais que vem sendo tomadas por tribunais brasileiros individual e separadamente no intuito de agregar uma série de valores à sua jurisdição. Entre estes valores, estão a celeridade, a publicidade, a operosidade, a praticidade e a universalidade.

Dentre os serviços mais comuns que hoje se encontram informatizados na maioria dos tribunais poderíamos enunciar: (i) o acompanhamento do andamento de processos na página do tribunal, (ii) o sistema 'push', onde o advogado se cadastra e recebe periodicamente por correio eletrônico as informações dos processos que patrocina, (iii) a consulta de jurisprudência (acórdãos e decisões) na página do tribunal, (iv) a divulgação de boletim informativo periódico do tribunal e $(v)$ o recebimento de petições via correio eletrônico ou fac-símile.

No entanto, espalhadas pelo país encontram iniciativas locais as quais merecem breve exame ${ }^{3}$.

Na Justiça do Trabalho, desde junho de 2002, por meio de convênio assinado com o BACEN, é possível efetuar a penhora "on line" de recursos depositados em quaisquer bancos do país e dificilmente localizados pelos credores nas execuções trabalhistas. Não haverá a quebra do sigilo bancário dos executados, uma vez que o sistema consiste no envio de um ofício eletrônico ao banco central informando a quantia devida e se o devedor possui tais recursos alocados em ativos financeiros.

Quanto à segurança de documentos eletrônicos, podemos citar o Tribunal de Justiça de São Paulo, que nos dias de hoje tem informatizado todo o serviço cartorial de emissão de certidões. Quatro são as rotinas de segurança utilizadas em São Paulo: $(i)$ os "dataglyphs", que nada mais são que uma seqüência numérica criptografada de todo o teor da certidão, sendo possível, inclusive, recuperar a mesma no caso de deterioração ou destruição parcial. Um código de barras de leitura (ii) vinculado às informações criptografadas complementa os "dataglyphs". Também é utilizado o selo digital (iii), impresso digitalmente em caracteres de 600 pontos por polegada, com caracteres ocultos, microletras e padrões geométricos, o que impede sua reprodução por cópia. Por fim, (iv) a assinatura eletrônica complementa o processo de atribuição de segurança e autenticidade das certidões eletrônicas. A despeito da contenção de gastos para o Tribunal com o antigo procedimento, envolvendo papel especial, selo holográfico, impressão matricial e chancela mecânica, o novo método logrou reduzir, de uma média de sete dias para 24 horas, o tempo da entrega da certidão, contado da data do pedido.

O Tribunal Regional do Trabalho de Santa Catarina vinculou os atos processuais ao portal do Tribunal na internet. Tal iniciativa, que possibilita aos patronos e às partes acessarem um grande número de informações processuais de quaisquer lugares onde possam manusear um micro computador conectado à rede, equiparam as possibilidades de acompanhamento dos recursos patrocinados por advogados no interior àqueles com escritório na capital, também reduziram o movimento nos cartórios judiciais de 50 a $60 \%$. A situação no Tribunal de Justiça do mesmo estado, amplamente informatizado, é de causar inveja: contam com cento e dez servidores de rede, três mil e quinhentos micro computadores, mil e duzentas impressoras e cento e cinqüenta roteadores.

\footnotetext{
${ }^{3}$ Todos descritos e com as fontes em Fontainha (2003).
} 
O Judiciário brasileiro importou a idéia de oitiva de presos por vídeo-conferência das cortes italianas e estadunidenses. Hoje, no Brasil, muitas Varas Criminais já encontram-se munidas de tal tecnologia, e, na grande São Paulo, a oitiva à distância de presos pouparia o trabalho de quinhentos policiais por dia.

Na Justiça Federal do Ceará, quando o então Governador extinguiu a Imprensa Oficial, os magistrados tiveram de recorrer à computação para a resolução do problema, dando cumprimento ao princípio constitucional da publicidade: publicar o diário da justiça em publicadoras digitais. No sistema original em offset, somando-se ao fato de a Justiça Federal, somente na Seção de Campina Grande, acumular mais de quarenta mil processos em andamento, com apenas quatro páginas e meia no periódico "A União", havia um atraso de noventa dias entre o expediente e a publicação das decisões. Hoje, o Diário da Justiça é publicado em tempo real, transferindo-se as informações da internet direto para a impressora, havendo um sistema que pagina e monta o caderno.

Todos estes exemplos revelam fatos os quais não podem escapar aos nossos auspícios. Em primeiro lugar, obtêm sucesso na empresa de dividir responsabilidades, uma vez que cada tribunal de cada competência desenvolve seu próprio feixe de sistemas computacionais periféricos. Em segundo lugar, têm obtido sucesso na criação de um aparato de garantias contra os possíveis riscos.

No entanto, a jurisprudência ainda não se solidificou no sentido de orientar a informatização dos tribunais e responsabilizar seus gestores. Tomando como paradigma as recentes decisões do Superior Tribunal de Justiça - STJ - tribunal ao qual, além de outras atribuiçõos, compete uniformizar a jurisprudência nacional em matéria infraconstitucional - podemos observar claramente esta contradição.

As ementas a seguir, oriundas das $1^{\mathrm{a}}$ e $3^{\mathrm{a}}$ Turmas do STJ, deixam claro que a parte envolvida no processo deve precisamente se valer dos meios tradicionais de comunicação dos tribunais, relegando às informações prestadas pelos recursos computacionais a pecha de "não oficiais".

RESP 572154/PR - RECURSO ESPECIAL - 2003/0142274-9 - Ministro JOSÉ DELGADO (relator) PRIMEIRA TURMA - 06/05/2004

PROCESSUAL CIVIL. PRAZO. SISTEMA DE INFORMAÇÕES PROCESSUAIS PRESTADAS PELA INTERNET. CITAÇÃO. AUSÊNCIA DE LANÇAMENTO DE INFORMAÇÃO DE JUNTADA DO MANDADO. PREJUÍZO. INEXISTÊNCIA.

1. As informações processuais prestadas por sítios eletrônicos da Justiça, ainda que se ressintam de credibilidade, não são dotadas de caráter oficial, amparado em Lei.

2. Não tendo havido erro ou equívoco na informação prestada, mas tão-somente demora em face das contingências da operacionalização da Justiça, não há que se falar em prejuízo à parte, que não adotou as medidas de cautela necessárias ao acompanhamento do processo pelos diversos meios disponíveis.

3. A inexistência do lançamento do andamento processual que indica a juntada do mandado de citação e penhora aos autos do processo não configura prejuízo à parte, a justificar a restituição de prazo para o oferecimento dos embargos do devedor, vez que, com a citação já se encontram presentes os subsídios suficientes ao oferecimento de defesa.

4. Recurso a que se nega provimento 
RESP 514412/DF - RECURSO ESPECIAL 2003/0053302-5 - Ministro CASTRO FILHO (relator) TERCEIRA TURMA - 02/10/2003

Processual civil. Intimação. Prazo. Internet.

I - As informações trazidas pela Internet têm natureza meramente informativa e não vinculativa, não podendo, pois, substituir a forma prevista em lei para contagem dos prazos processuais.

II - Recurso especial conhecido mas desprovido.

Por outro lado, outras decisões, oriundas da $2^{\mathrm{a}}$ e $4^{\mathrm{a}}$ turma do mesmo Tribunal, em épocas próximas e recursos de mesma natureza processual, vão aliviar as partes de equívocos porventura ocorridos nas informações prestadas eletronicamente, sob o principal argumento de que os usuários do sistema confiam nas informações prestadas, chegando até a afirmar que com a vinculação das datas de publicação pela rede se torna supérflua a consulta ao Diário Oficial, como se vê:

RESP 538642/RS - RECURSO ESPECIAL - 2003/0058826-1 - Ministro CESAR ASFOR ROCHA (relator) - QUARTA TURMA - 09/09/2003

PROCESSUAL CIVIL. CONTAGEM DE PRAZO PARA CONTESTAÇÃO. SERVIÇO OFICIAL DE INFORMÁTICA. INFORMAÇÃO EQUIVOCADA.

É justificável o equívoco cometido pela parte fora do prazo regular se a tanto foi induzida por informação errada ou imprecisa obtida no serviço oficial de informações posto à disposição das partes e dos seus advogados pelo próprio Poder Judiciário. Todavia, na espécie, não houve informação equivocada quanto à data de juntada do mandado, porém mera omissão. Ademais, a juntada do cumprimento do mandado é ato que independe de intimação, sendo desimportante para o início do prazo da contestação a ciência da parte quanto a esse ato em particular e, por conseguinte, não constituindo justa causa eventual informação equivocada.

Recurso não conhecido.

RESP 557103/MG - RECURSO ESPECIAL - Ministro FRANCIULLI NETTO (relator) - SEGUNDA TURMA - 01/04/2004 - 2003/0130702-9

PROCESSO CIVIL - ACOMPANHAMENTO PROCESSUAL PELO SISTEMA DE INFORMATIZAÇÃO DO TRIBUNAL (INTERNET) - INFORMAÇÃO ERRÔNEA OU IMPRECISA, DE MODO A OBSTAR A PRÁTICA DE ATO PROCESSUAL EM TEMPO - PRETENDIDO RECONHECIMENTO DE JUSTA CAUSA - ACOLHIMENTO - RECURSO ESPECIAL PROVIDO.

- Se colocado à disposição o serviço de internet pelo Tribunal, deve ser prestado eficazmente, pois todos os jurisdicionados confiam nas informações prestadas. A propósito, a ilustre Ministra Eliana Calmon, em situação ocorrida neste Sodalício, elucidou que, "no momento em que há publicação das decisões pela internet, tendo criado o Tribunal, inclusive, a Revista Eletrônica, é um contra-senso falar em tempestividade recursal a partir da publicação pelo DJU". Em outro passo, com a mesma ênfase, adverte a douta Ministra que "a demora na publicação das decisões, via Imprensa Oficial, não coloca o Judiciário em condições de cobrar dos causídicos o acompanhamento das lides pelo Diário Oficial" (cf. Ag. Reg. Nos Emb. Decl. no REsp 262.316-PR, DJ 7/10/2002).

- As informações que foram apresentadas de modo incorreto ou impreciso pelo serviço de informatização, configuram justa causa a autorizar que a parte prejudicada pratique o ato que deixou de efetivar quando induzida em erro. Precedentes da $1^{\mathrm{a}}$ e $4^{\mathrm{a}}$ Turmas desta Corte Superior de Justiça. 
- Recurso especial conhecido e provido.

\section{Da certificação digital}

Ao contrário do recorte anterior, existe um só plano nacional para informatizar o processo judicial. Este plano está incorporado do Anteprojeto de Lei Sobre a Informatização do Processo Judicial, de autoria da AJUFE - Associação dos Juízes federais do Brasil e sob a relatoria do Deputado Ney Lopes. ${ }^{4}$ O projeto se limita a regulação do uso de meio eletrônico na comunicação de atos e a transmissão de peças processuais, ou seja, visa a criação de uma rede de usuários cadastrados, onde suas firmas serão substituídas por assinaturas digitais, seja a firma do advogado num recurso, a do juiz numa sentença ou a de um serventuário num mandado de intimação.

Ocorre que tal projeto se articula com a ICP-Brasil, Infra-Estrutura de Chaves Públicas, instituída pela Medida Provisória 2.200 de 2001. A partir desta medida, a Presidência da República passa a administrar e centralizar a responsabilidade por todos os sistemas de certificação digital no Brasil. Públicos ou privados.

É despiciendo mencionar que um leitor atento não deixaria passar despercebido que há uma tendência absolutizante de centralização de responsabilidades neste caso. Por exemplo, se um 'cracker' falsificar uma sentença digital, é a entidade certificadora que arca com as conseqüências e fica responsável por eventuais danos causados.

\section{Conclusões}

O castelo de certezas da modernidade chegou aos anos oitenta sob a constatação de que havia construído suas fundações sobre solo menos seguro que imaginara. A pretensa vitória da ciência sobre a religião foi reduzida a menor destaque, uma vez que a ciência e seu papel revelador da verdade e da realidade foi incapaz de criar um mundo colonizado e manobrável pelo homem. Torna-se reflexiva a modernidade a partir do momento em que é forçada a rever as bases sobre as quais se construiu, donde um novo ethos emerge: evitar riscos, otimizar custos e majorar benefícios, na empresa de se construir a boa sociedade, a boa vida, um lugar seguro dentro de ambas... Depois a verdade. No entanto, a sociedade de risco não significa a interrupção da vida, porém apenas uma alteração na subjetividade das atividades humanas.

Não poderia deixar de ser de forma semelhante com um novíssimo mundo da vida virtual, criado a partir da expansão de novas mídias intermediando relações humanas. Da mesma forma que o mundo face-a-face, o mundo virtual também incorpora o ethos da segurança, da precaução, sendo o retrato perfeito da universalidade e globalização dos riscos. É também da informática o principal paradigma a segurança, que, como vimos, é calcada principalmente na certeza da distribuição das responsabilidades.

\footnotetext{
${ }^{4}$ Consulta completa a partir do link: federativo.bndes.gov.br/destaques/egov/docs/ajufe.pdf.
} 
Tivemos a oportunidade de perceber, em linhas gerais, como ocorre a informatização do Poder Judiciário no Brasil. Em ambos os recortes que traçamos, é presente a preocupação em garantir a segurança dos novos sistemas informatizados, seja pela atribuição de responsabilidades ao tribunal que gerencia a página eletrônica, seja pelo Poder Executivo Federal.

Não podemos deixar de mencionar que a tendência centralizadora do Poder Executivo na questão da certificação digital, a despeito de qualquer juízo de valor, é incondizente com os parâmetros de atribuição de segurança. Seria um esforço louvável a divisão da responsabilidade com outros entes estatais ou com entidades da sociedade civil organizada. Por que cada tribunal não pode certificar a assinatura de seus juízes e serventuários? Por que a OAB não certifica a assinatura de seus advogados afiliados? Por que sindicatos, associações e mesmo ONGs não podem ter parcela desta responsabilidade? Seria, ao menos, mais condizente com nosso tempo.

\section{Referências}

ADAM, B.; BECK, U.; VAN LOON, J. (Org.) The risk society and beyond: critical issues for social theory. Londres: Sage, 2000.

BAKER, T. Risk. Insurance, and the social construction of responsibility. In: BAKER, T.; SIMON, J. (Org.). Embracing risk: the changing culture of insurance and responsibility. Chicago: University of Chicago Press, 2002.

BAKER, T.; SIMON, J. (Org.). Embracing risk: the changing culture of insurance and responsibility. Chicago: University of Chicago Press, 2002.

BECK, U. Risk society revisited: theory, politics and research programmes. In: ADAM, B.; BECK, U.; LOON, J. Van (Org.) The risk society and beyond: critical issues for social theory. Londres: Sage, 2000.

Risk society: towards a new modernity. Londres: Sage, 1992.

BECK, U.; ZOLO, D. La società globale del rischio: una discussione fra Ulrich Beck e Danilo

Zolo. Swif: sito web italiano per la filosofia, 1999. Disponível em: <http://lgxserver.uniba.it/lei/filpol/zolobeck.htm>. Acesso: 12 mar. 2004.

BENTHAM, G. Uma introdução aos princípios da moral e da legislação. São Paulo: Abril, 1979.

DESCARTES, R. Discurso sobre o método. In: DESCARTES. São Paulo: Nova Cultural., 1996. (Coleção Os Pensadores).

. Meditações metafísicas. In: DESCARTES. São Paulo: Nova Cultural, 1996. (Coleção Os Pensadores).

DESEMBARGADOR reconhece falhas diárias no sistema do TJ. Jornal Do Brasil, Rio de Janeiro, 30 abr. 2004. Caderno 1, p. A2.

DOUGLAS, M. Purity and danger. Nova York: Routledge, 2002. 
DOUGLAS, M.; WILDAVSKY, A. Risk and culture. Los Angeles: University of Califórnia Press, 1982.

EWALD, François. The return of Descartes's malicious demon: an outline of a philosopy of precaution. In: BAKER, T.; SIMON, J. (Org.). Embracing risk: the changing culture of insurance and responsibility. Chicago: University of Chicago Press, 2002.

FONTAINHA, F. C. Discutindo a informatização do processo no contexto do acesso e administração da justiça: o pioneirismo do TRF3. Mundo Jurídico, [Rio de Janeiro]. Disponível em: <http://www.mundojuridico.adv.br/html/artigos/documentos/texto190.htm>. Consulta em: 3 ago. 2003.

GIDDENS, A. As conseqüências da modernidade. São Paulo: Ed. Unesp, 1990.

Modernidade e identidade. Rio de Janeiro: J. Zahar, 2002.

LOON, J. V. Virtual risks in the age of cybernetic reproduction. In: ADAM, B.; BECK, U.; LOON, J. Van (Org.) The risk society and beyond: critical issues for social theory. Londres: Sage, 2000.

ROSE, H. Risk, trust and scepticism in the age of the new genetics. In: ADAM, B.; BECK, U.; LOON, J. Van (Org.) The risk society and beyond: critical issues for social theory. Londres: Sage, 2000.

ROSE, N. At risk of madness. In: BAKER, T.; SIMON, J. (Org.). Embracing risk: the changing culture of insurance and responsibility. Chicago: University of Chicago Press, 2002.

SINGER, P. Animal liberation. Nova York: Harper Collins Publishers, 2002.

WEBER, M. A “objetividade” do conhecimento nas ciências sociais. In: COHN, G. (Org.). Weber. São Paulo: Ática. 1991. (Coleção Grandes Cientistas Sociais).

. Ciência e política: duas vocações. São Paulo: Cultrix, 2002.

Economia y sociedad. México, DF: Fondo de Cultura Económica, 1944. v. 1. 